\title{
Non-Verbal and Verbal Fluency in Prodromal Huntington's Disease
}

\author{
Tarja-Brita Robins Wahlin ${ }^{a, c}$ Mary A. Luszcz ${ }^{d}$ Åke Wahlin ${ }^{b}$ \\ Gerard J. Byrne ${ }^{c}$ \\ a Division of Clinical Geriatrics, Department of Neurobiology, Care Sciences and Society,

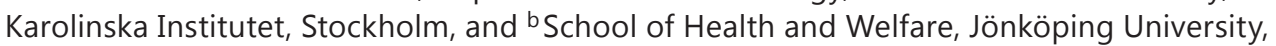 \\ Jönköping, Sweden; 'SChool of Medicine, University of Queensland, Brisbane, Qld., and \\ ${ }^{\mathrm{d} S}$ School of Psychology, Flinders University, Adelaide, S.A., Australia
}

\author{
Key Words \\ Prodromal Huntington's disease · Cognition · Neuropsychology · Non-verbal fluency · \\ Phonemic fluency Semantic fluency . Executive functioning
}

\section{Abstract}

Background: This study examines non-verbal (design) and verbal (phonemic and semantic) fluency in prodromal Huntington's disease (HD). An accumulating body of research indicates subtle deficits in cognitive functioning among prodromal mutation carriers for HD. Methods: Performance was compared between 32 mutation carriers and 38 non-carriers in order to examine the magnitude of impairment across fluency tasks. The predicted years to onset (PYTO) in mutation carriers was calculated by a regression equation and used to divide the group according to whether onset was predicted as less than 12.75 years (HD+CLOSE; $n=16$ ) or greater than 12.75 years (HD+DISTANT; $n=16$ ). Results: The results indicate that both nonverbal and verbal fluency is sensitive to subtle impairment in prodromal HD. HD+CLOSE group produced fewer items in all assessed fluency tasks compared to non-carriers. HD+DISTANT produced fewer drawings than non-carriers in the non-verbal task. PYTO correlated significantly with all measures of non-verbal and verbal fluency. Conclusion: The pattern of results indicates that subtle cognitive deficits exist in prodromal HD, and that less structured tasks with high executive demands are the most sensitive in detecting divergence from the normal range of functioning. These selective impairments can be attributed to the early involvement of frontostriatal circuitry and frontal lobes.

(C) 2015 The Author(s)

Published by S. Karger AG, Basel 
Robins Wahlin et al.: Non-Verbal and Verbal Fluency in Prodromal Huntington's Disease

\section{Introduction}

Huntington's disease (HD) is associated with motor disturbances, psychiatric symptoms, and cognitive impairment [1-6]. An accumulating body of research has postulated the existence of a prodromal phase of HD. Evidence comes from both neuropsychological [7-16] and imaging data [16-20]. There are alterations in cognitive functioning, as well as in brain structure, before motor symptoms are evident $[18,20]$. The predominant pathology in HD is found in the basal ganglia, with distinct changes in the caudate nucleus and putamen [21-23]. Subsequent cell loss occurs in other subcortical and cortical areas of the brain [19]. Basal ganglia atrophy $[24,25]$ and the loss of striatal dopamine D1 and D2 receptors [26, 27] cause dysfunction in the frontostriatal circuits [28]. The performance of fluency tasks relies on the integrity of striatum, frontal lobes and frontostriatal circuitry, and to some degree temporal lobes [27, 29-31]. Although fluency tasks are widely used, and easy and quick to administer, it remains unclear which fluency tasks best capture the prodromal phase in HD. The picture is unclear due to the dearth of studies that track fluency domains in prodromal HD.

Phonemic and semantic fluency was investigated by Larsson et al. [32] in a previous prodromal HD study. It was found that phonemic fluency is more sensitive than semantic fluency in the prodromal phase, and the authors speculated that the results pointed towards frontostriatal, rather than temporal, involvement [32]. However, the frontostriatal circuits are present in each hemisphere [28] and both semantic and phonemic fluency are accompanied by a language component [33,34]. As the left frontal lobe is primarily engaged in the production of verbal responses in normal adults $[33,34]$, and difficulties with verbal fluency tasks have been associated with left frontal lobe pathology [31], it would be clarifying to use a task that minimizes linguistic demands on fluency performance in prodromal HD. This present study aims to extend previous findings by assessing non-verbal fluency and comparing it with verbal (phonemic and semantic) fluency assessed at the same time point. A non-verbal fluency task, Design Fluency, developed by Jones-Gotman and Milner [35], assesses the ability to produce abstract designs during a time constraint. This non-verbal counterpart to phonemic and semantic fluency has revealed deficits in patients with right frontal and right frontocentral lesions [35]. However, more recent research suggests that Design Fluency is dependent on both left and right frontal lobes [31,33]. Accordingly, we hypothesize that (1) the bilateral dependency of Design Fluency could prove the test to be a sensitive marker of cognitive functioning in prodromal HD and (2) mutation carriers closer to disease onset would consequently be less proficient than non-carriers in all fluency tasks.

To test these hypotheses, we measured the magnitude of impairment in the three different fluency tasks and compared these measures within the mutation carrier group and with non-carriers. The objectives of the study were 3 -fold. First, our primary goal was to discriminate [36] between the three different fluency tasks and to evaluate the magnitude of impairment revealed by the tasks. Second, as earlier research has shown an association between time to disease onset and cognitive functioning in prodromal samples [12, 37, 38], we aimed to examine this association using bivariate correlations between fluency performance in the carrier group and predicted years to onset (PYTO). Finally, non-verbal, phonemic, and semantic fluency was assessed at the same time point to test the generality of these findings. Hence, this study aimed to address, for the first time, the pattern of fluency performance by conducting and comparing concurrent non-verbal, phonemic, and semantic fluency tasks in the same sample. 
Robins Wahlin et al.: Non-Verbal and Verbal Fluency in Prodromal Huntington's Disease

\section{Materials and Methods}

\section{Participants}

Genetic counselling for HD at Karolinska University Hospital, Stockholm, was established in 1990 [39]. Individuals, who (1) participated in a psychosocial programme within the genetic testing programme, (2) underwent neurological and psychiatric examination, (3) received information of their genetic status, and (4) did not have any other disease that affected their cognition, were qualified to enter a neuropsychological study. Participants entering the neuropsychological study were not invited if they currently or previously had met criteria for manifest HD [40] or if they had a history of other neurological disability, major psychiatric disturbances, or a history of alcohol and/or substance abuse. Neurological examinations were conducted by an experienced neurologist and in accordance with the recommendations of Folstein et al. [41] until 1996, when the current project adopted the Unified Huntington's Disease Rating Scale [42]. HD mutation carriers and non-carriers (hereinafter called carriers or non-carriers, respectively) were at risk of inheriting HD and voluntarily requested genetic counselling. Hence, recruitment of carriers and non-carriers was based on the same motor and cognitive criteria and the non-carriers served as the control group in the present study.

To determine carrier status, linkage analyses were performed until 1993 when the specific genetic marker, a CAG trinucleotide repeat, was discovered by Huntington's Disease Collaborative Research Group. All participants tested before $1993(n=7)$ received mutation analysis except for one carrier who developed minor signs of HD 8 years after the initial neuropsychological testing and was therefore included. Of all participants in the neuropsychological study tested from December 1990 until August 2012, 32 individuals proved to have CAG repeat lengths of 37 or greater and 39 individuals had normal HD alleles, having repeat lengths of 33 or less [5,43]. One non-carrier was excluded from this study due to brain damage from a motor vehicle accident. Hence, 70 individuals, 32 carriers (HD+) and 38 noncarriers (HD-) were included in the study (table 1).

All procedures complied with the Helsinki Declaration and the study was approved by the Ethics Committee of the Karolinska University Hospital, Stockholm, Sweden. All participants were informed of confidentiality and gave formal written consent to participate in the study. Only those who had travelling expenses received a small remuneration towards the expenses. The recruitment of participants is described in detail elsewhere [44].

The demographic and genetic characteristics of the participants are summarized in table 1 . The age ranged between 20 and 61 years in the total sample. A total of 12 carriers have been diagnosed with HD since the start of the programme, providing the opportunity to determine how far from disease onset they were at the time of neuropsychological testing. For the remaining 20 mutation carriers, estimated age at onset was calculated using a regression equation described by Langbehn et al. [43, 45]. PYTO were calculated by subtracting the current age from the estimated age at onset. Years to onset were analyzed, using real years to onset when known and predicted years for the remaining carriers, and found to be positively skewed (skewness $=1.269, \mathrm{SE}=0.414$ ). Median split of the carrier group was performed into two groups using the median years to onset ( $M d=12.75)$ : carriers with less than 12.75 years (range $1-12.64$ ) to disease onset (HD+CLOSE; $n=16$ ) and carriers with 12.75 years or more (range 12.85-50.55) to disease onset (HD+DISTANT; $\mathrm{n}=16)$.

\section{Procedure}

The participants in the study each underwent separately a comprehensive neuropsychological assessment. The entire assessment took place during 1 day, and the tests were admin- 
Robins Wahlin et al.: Non-Verbal and Verbal Fluency in Prodromal Huntington's Disease

Table 1. Demographic and genetic characteristics for HD+CLOSE ( $<13$ PYTO), HD+DISTANT ( $\geq 13$ PYTO) and non-carriers

\begin{tabular}{|c|c|c|c|c|c|c|}
\hline & \multirow{2}{*}{$\begin{array}{l}\text { HD+CLOSE } \\
(n=16 ; \\
\text { group } 1)\end{array}$} & \multirow{2}{*}{$\begin{array}{l}\text { HD+DISTANT } \\
(\mathrm{n}=16 ; \\
\text { group } 2)\end{array}$} & \multirow{2}{*}{$\begin{array}{l}\text { HD- } \\
(n=38 ; \\
\text { group 3) }\end{array}$} & \multicolumn{3}{|c|}{ Group comparison $\mathrm{p}^{\mathrm{g}}$} \\
\hline & & & & $1-3$ & $1-2$ & $2-3$ \\
\hline Male gender ${ }^{\mathrm{a}}$ & $9(56.3)$ & $8(50)$ & $15(39.5)$ & n.s. & n.s. & n.s. \\
\hline Age, years ${ }^{\mathrm{b}}$ & $37.7 \pm 10.4$ & $32.4 \pm 7.4$ & $36.9 \pm 10.1$ & n.s. & n.s. & n.s. \\
\hline Education, years ${ }^{\mathrm{b}}$ & $12.2 \pm 2.4$ & $12.9 \pm 3.2$ & $12.8 \pm 2.7$ & n.s. & n.s. & n.s. \\
\hline Estimated age at onset, years ${ }^{b}$ & $46.9 \pm 10.7$ & $57.6 \pm 16.0$ & - & & & \\
\hline \multicolumn{7}{|l|}{ Use of medications, frequency } \\
\hline Antidepressives ${ }^{c}$ & 3 & 2 & 0 & 0.023 & n.s. & n.s. \\
\hline Neuroleptics ${ }^{\mathrm{c}}$ & 0 & 0 & 0 & n.s. & n.s. & n.s. \\
\hline Benzodiazepines $^{\mathrm{c}}$ & 2 & 0 & 2 & n.s. & n.s. & n.s. \\
\hline Asthma/allergy $^{c}$ & 1 & 1 & 1 & n.s. & n.s. & n.s. \\
\hline Other ${ }^{\mathrm{c}, \mathrm{d}}$ & 6 & 2 & 13 & n.s. & n.s. & n.s. \\
\hline \multicolumn{7}{|c|}{ Wechsler Adult Intelligence Scale - Revised } \\
\hline Full-scale IQ ${ }^{\mathrm{b}}$ & $85.4 \pm 11.2$ & $97.9 \pm 14.3$ & $106.0 \pm 16.8$ & $<0.001$ & n.s. & n.s. \\
\hline Verbal IQ ${ }^{\mathrm{b}}$ & $89.9 \pm 13.8$ & $96.1 \pm 13.8$ & $104.1 \pm 15.6$ & 0.006 & n.s. & n.s. \\
\hline Performance IQ ${ }^{\mathrm{b}}$ & $82.7 \pm 11.4$ & $101.2 \pm 13.9$ & $107.6 \pm 17.3$ & $<0.001$ & 0.003 & n.s. \\
\hline CAG size of the expanded allele & $43.4 \pm 2.4^{\mathrm{e}}$ & $42.0 \pm 3.2$ & $20.7 \pm 4.0$ & $<0.001$ & n.s. & $<0.001$ \\
\hline Range & $39-47$ & $37-48$ & $16-33$ & & & \\
\hline CAG size of the normal allele & $18.9 \pm 2.0$ & $18.1 \pm 3.2$ & $17.0 \pm 2.2$ & $<0.01$ & n.s. & n.s. \\
\hline Range & $16-25$ & $10-21$ & $11-21$ & & & \\
\hline Estimated years to onset ${ }^{f}$ & $7.3 \pm 4.2$ & $24.0 \pm 10.6$ & & - & $<0.001$ & - \\
\hline Estimated age at onset ${ }^{\mathrm{f}}$ & $46.9 \pm 10.7$ & $57.6 \pm 16.0$ & & - & 0.033 & - \\
\hline
\end{tabular}

Values represent $\mathrm{n}(\%)$, mean $\pm \mathrm{SD}$ or $\mathrm{n} .{ }^{\mathrm{a}}$ Pearson's $\chi^{2}$ test. ${ }^{\mathrm{b}}$ Student's t test. ${ }^{\mathrm{c}}$ Fisher's exact test. ${ }^{\mathrm{d}}$ Other medications refer to contraceptives, migraine medication and hormone replacement therapy. ${ }^{\mathrm{e}} \mathrm{n}=15$; one participant's CAG repetition was not known (the participant had manifest disease 8 years after linkage testing). ${ }^{\mathrm{f}}$ Estimation was calculated by using the formula proposed by Langbehn et al. [43]. ' Univariate mean comparisons reported except for sex of affected parent where Pearson's $\chi^{2}$ test was used.

istered, by an experienced psychologist, in the same sequence to each individual. The assessment took 5-6 $\mathrm{h}$ to complete. In order to avoid effects of fatigue, there were two breaks, one after $2 \mathrm{~h}$ of testing (lunch break) and another after a further 90 -min testing session. Information about the entire test battery is published elsewhere [7, 32, 46, 47].

\section{Instruments}

Phonemic Fluency (S:A Test) [48]. This test requires the participant to orally produce as many words as possible beginning with $S$ and ending with $A$. The Swedish language is fairly rich in words beginning with $S$ and ending with $A$. To minimize a possible effect of automatic, rapid fluency, which takes place in the first $30 \mathrm{~s}$ [49], a 3-min time period was used [48]. The subjects were instructed to exclude proper names and numbers. The total number of words, perseverations, and rule violations was also recorded.

Semantic Fluency (Category Fluency) [29]. Two semantic fluency tasks, fruits and vegetables, were administered. The semantic fluency task requires the participant to say as many words as possible belonging to the categories of fruits and vegetables, respectively, within a 1-min time constraint. The task was scored by counting the total number of words produced as well as perseverations and rule violations. The two categories, fruits and vegetables, were significantly correlated $(\mathrm{r}=0.54, \mathrm{p}<0.001)$ and were therefore summed to create a composite measure of semantic fluency in the analyses. 
Fig. 1. Hypothetical Design Fluency drawings that represent neither actual objects nor nameable abstract forms.

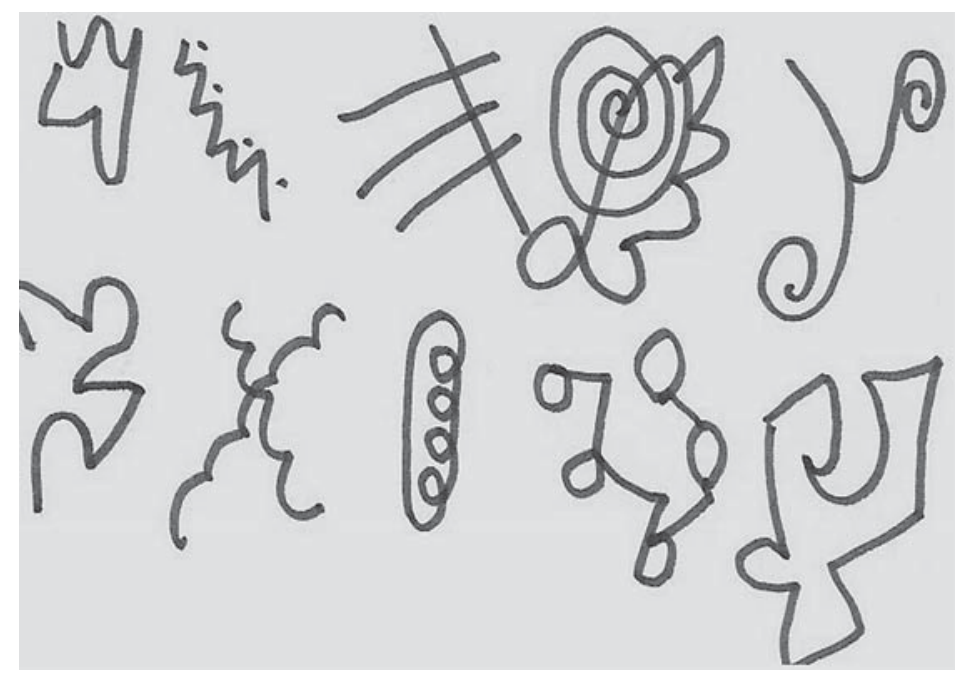

Non-Verbal Fluency (Design Fluency) [29]. The free condition of Design Fluency described by Jones-Gotman and Milner [35] was used (the fixed four-line condition was not used, see fig. 1).

The subjects were asked to produce as many drawings as they could within $5 \mathrm{~min}$. They were instructed that the drawings must not represent real objects or be derived from such an object, and that they must not draw any abstract pattern that could be named, such as a geometric form. Finally, they were instructed that scribbling was not allowed due to the tendency for scribbles to look too much alike and the purpose of the task was to draw as many different designs as possible. The participants were presented with two exemplars of drawings representing allowed and not allowed sketches, which were discussed before the test. All participants were allowed one warning if they did not follow the rules given. The task was scored by counting the total number of novel responses, perseverations, and objects that could be named (rule violations).

\section{Statistical Analysis}

The Statistical Package for Social Sciences (SPSS) 22.0 was used for all statistical calculations. For demographic variables univariate mean comparisons and $\chi^{2}$ tests were computed where appropriate. The non-verbal fluency, phonemic fluency, and semantic fluency were compared using multivariate analysis of variance (MANOVA) with group (HD+CLOSE, HD+DISTANT, and HD-) as a between-subject factor followed by univariate ANOVAs. An alpha level of 0.05 was used and SPSS standard Bonferroni correction applied for multiple post hoc comparisons, such that the calculated p value was multiplied by 3 (i.e., the number of comparisons per outcome variable) before being reported. The same procedure was applied to the sum of errors on the non-verbal, phonemic, and semantic fluency tasks, respectively. Bivariate correlations (Pearson's r) were conducted between fluency performance and PYTO to examine the relationship between fluency and estimated time to disease onset. In order to compare performance across tasks within the carrier groups (HD+CLOSE and HD+DISTANT) raw scores were converted to z-scores based on the performance of the control group (the HD- group). Paired t tests were assessed for the z-scores of carriers in order to compare the three fluency tasks. Measures of effect size are reported as Cohen's d and partial $\eta^{2}$. 
Robins Wahlin et al.: Non-Verbal and Verbal Fluency in Prodromal Huntington's Disease

Table 2. Mean scores for phonemic fluency, semantic fluency, non-verbal fluency, and fluency errors (rule violations) by group

\begin{tabular}{|c|c|c|c|c|c|c|}
\hline & \multirow{2}{*}{$\begin{array}{l}\text { HD+CLOSE } \\
(n=16 ; \\
\text { group 1) }\end{array}$} & \multirow{2}{*}{$\begin{array}{l}\text { HD+DISTANT } \\
(\mathrm{n}=16 ; \\
\text { group } 2)\end{array}$} & \multirow{2}{*}{$\begin{array}{l}\text { HD- } \\
(n=38 ; \\
\text { group 3) }\end{array}$} & \multicolumn{3}{|c|}{ Group comparisons $\mathrm{p}^{\mathrm{a}}$} \\
\hline & & & & $1-3\left(d^{b}\right)$ & $2-3\left(d^{b}\right)$ & $1-2\left(d^{b}\right)$ \\
\hline Non-verbal fluency & $12.9 \pm 4.7$ & $18.3 \pm 8.5$ & $24.1 \pm 8.1$ & $<0.001(-1.52)^{*}$ & $0.036(-0.70)^{*}$ & $0.151(-0.77)$ \\
\hline Phonemic fluency & $20.1 \pm 10.2$ & $27.6 \pm 8.9$ & $32.2 \pm 9.6$ & $<0.001(-1.22)^{*}$ & $0.322(-0.48)$ & $0.096(-0.76)$ \\
\hline Semantic fluency & $19.7 \pm 4.9$ & $24.2 \pm 5.5$ & $24.9 \pm 7.0$ & $<0.022(-0.79)^{*}$ & $1.000(-0.10)$ & $0.143(-0.84)$ \\
\hline Non-verbal fluency errors ${ }^{c}$ & $3.0 \pm 3.1$ & $2.3 \pm 3.7$ & $1.1 \pm 1.5$ & $<0.043(0.90)^{*}$ & $0.363(0.50)$ & $1.000(0.20)$ \\
\hline Phonemic fluency errors ${ }^{\mathrm{d}}$ & $1.9 \pm 1.8$ & $1.0 \pm 1.4$ & $1.1 \pm 1.2$ & $0.234(0.56)$ & $1.000(-0.08)$ & $0.241(0.54)$ \\
\hline Semantic fluency errors ${ }^{d}$ & $1.8 \pm 2.4$ & $1.6 \pm 1.8$ & $0.9 \pm 0.9$ & $0.178(0.59)$ & $0.462(0.56)$ & $1.000(0.09)$ \\
\hline
\end{tabular}

Values represent mean $\pm \mathrm{SD} .{ }^{*} \mathrm{p}<0.05$. ${ }^{\mathrm{a}}$ Group comparisons performed using Bonferroni adjustment. ${ }^{\mathrm{b}}$ Cohen's d calculated using pooled standard deviation. ${ }^{\mathrm{c}}$ Non-verbal fluency errors are the sum of perseverations and nameable drawings. ${ }^{\mathrm{d}}$ Errors are the sum of confabulations and perseverations.

\section{Results}

\section{Non-Verbal and Verbal Fluency by Group}

Table 2 displays the mean performance for 6 fluency task variables by the HD+CLOSE, HD+DISTANT, and HD- groups. A MANOVA yielded a significant effect of group in total production of designs and words combined $[\mathrm{F}(6,130)=5.19, \mathrm{p}<0.001$; Wilks's $\lambda=0.65$; $\left.\eta^{2}=0.19\right]$. Analysis of each individual dependent variable revealed a significant effect of the group on non-verbal fluency $\left[\mathrm{F}(2,67)=12.92\right.$, $\left.\mathrm{MSE}=57.45, \mathrm{p}<0.001 ; \eta^{2}=0.28\right]$, phonemic fluency $\left[\mathrm{F}(2,67)=9.02, \mathrm{MSE}=92.34, \mathrm{p}<0.001 ; \eta^{2}=0.21\right]$, and semantic fluency $[\mathrm{F}(2,67)=$ 3.94, $\left.\mathrm{MSE}=39.30, \mathrm{p}=0.024 ; \eta^{2}=0.11\right]$. The Bonferroni post hoc test revealed a significant difference in non-verbal fluency between the HD+CLOSE and the HD- groups, $p<0.001$, and between the HD+DISTANT and the HD- group, $p=0.036$, but not between the two carrier groups. Furthermore, a significant difference was found between the HD+CLOSE and the HDgroups in phonemic fluency, $p<0.001$, and semantic fluency, $p=0.022$, but no reliable difference between the HD+DISTANT and the HD- group, or between the HD+CLOSE and the HD+DISTANT group.

\section{Magnitude of Differences across Fluency Tasks}

Because no significant differences emerged between the two HD+ groups, and to be able to compare the magnitude of impairments across fluency tasks, the data of the HD+CLOSE and the HD+DISTANT group were combined into a single group. Figure 2 displays the mean standardized scores of carriers relative to the performance of non-carriers on each fluency task. Paired t tests revealed that performance in non-verbal fluency was lower relative to semantic fluency $[\mathrm{t}(31)=3.77, \mathrm{p}<0.001, \mathrm{~d}=0.67]$, and phonemic fluency was lower relative to semantic fluency $[\mathrm{t}(31)=2.90, \mathrm{p}=0.007, \mathrm{~d}=0.51]$; however, no significant difference was observed between non-verbal and phonemic fluency $(d=0.13)$.

\section{Fluency Performance in Relation to PYTO}

Bivariate correlations were conducted to determine the relationship between fluency performance and PYTO. The correlation for non-verbal fluency was $r=0.35, p=0.048$, for phonemic fluency $r=0.49, p=0.004$, and for semantic fluency $r=0.43, p=0.014$ (fig. 3 ). 
Robins Wahlin et al.: Non-Verbal and Verbal Fluency in Prodromal Huntington's Disease

Fig. 2. Mean fluency z-scores for carriers relative to non-carriers. Error bars represent standard errors around the mean. ${ }^{*} \mathrm{p}<0.05$.

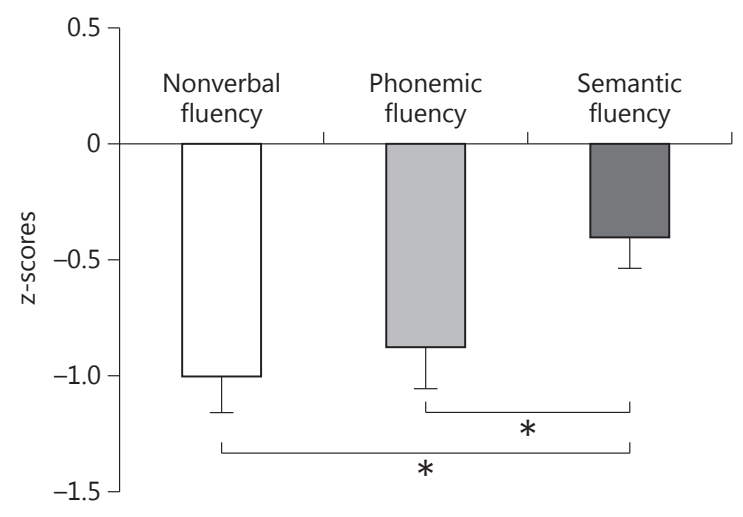

Fig. 3. Performance across fluency tasks for the gene carriers by PYTO. a Non-verbal fluency ( $\mathrm{r}=$ $0.35, \mathrm{p}=0.048)$. b Phonemic fluency $(r=0.49, p<0.01)$. c Semantic fluency $(r=0.43, p=0.01)$. The regression line is the non-linear quadratic component.
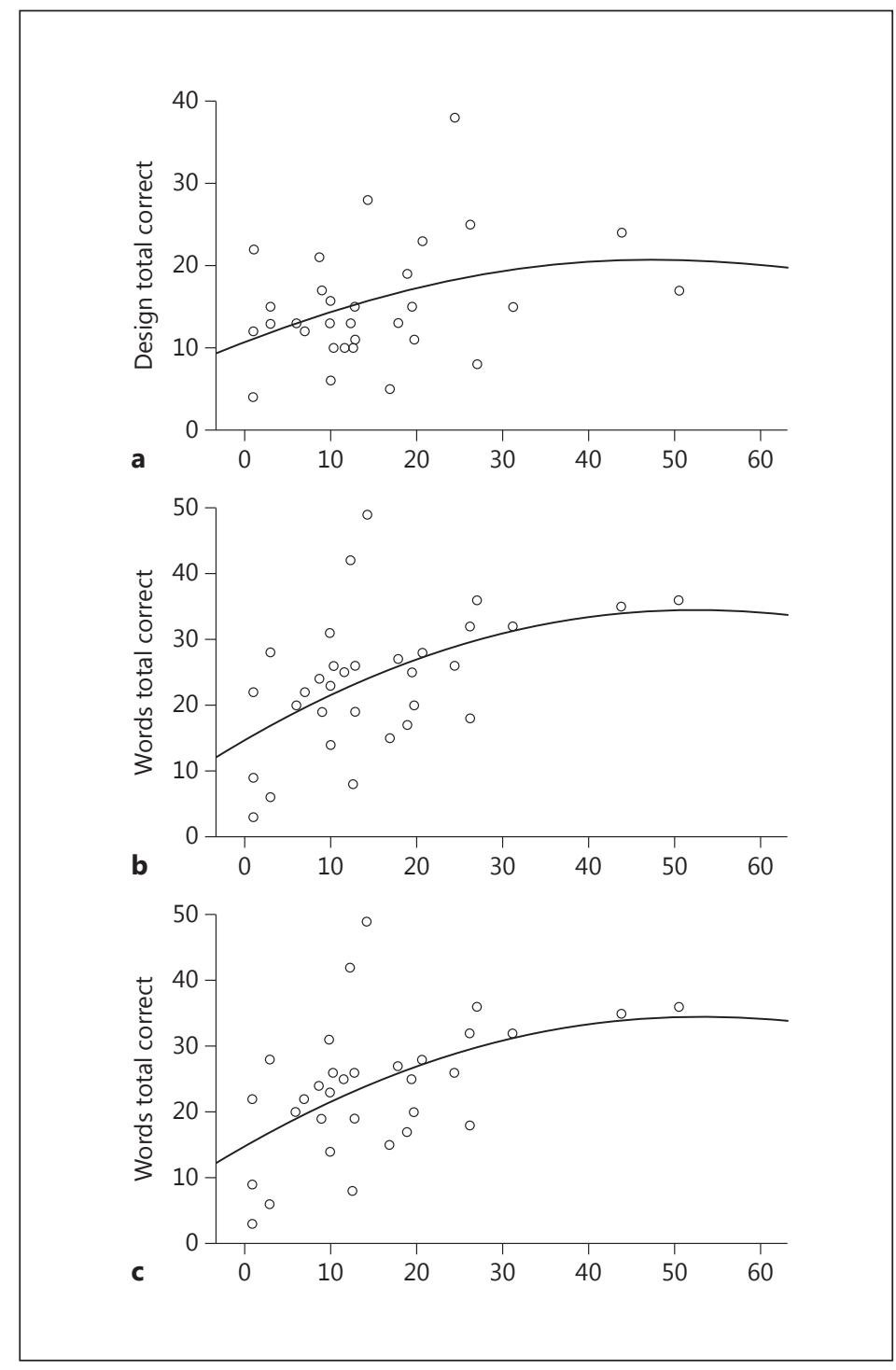


\section{Error Analyses}

A MANOVA was performed on the sum of errors on the phonemic, semantic, and nonverbal fluency tasks. This yielded a significant effect of the group on the combined error measures $\left[F(6,130)=2.25, p=0.043\right.$; Wilks's $\left.\lambda=0.82 ; \eta^{2}=0.09\right]$. ANOVAs were performed for the sum of errors on the phonemic, semantic, and non-verbal fluency tasks, respectively. A significant effect of the group was found for non-verbal fluency $[F(2,67)=3.54, \operatorname{MSE}=6.50$, $\left.p=0.035 ; \eta^{2}=0.10\right]$. Bonferroni post hoc comparisons resulted in a significant difference between the HD+CLOSE and the HD- groups on non-verbal fluency errors ( $p=0.043$ ). No significant effects of group were found for phonemic $[\mathrm{F}(2,67)=2.00, \mathrm{MSE}=1.94, \mathrm{p}=0.144]$ and semantic fluency $[\mathrm{F}(2,67)=2.26$, MSE $=2.48, \mathrm{p}=0.112]$.

\section{Discussion}

This study aimed to compare non-verbal and verbal fluency in prodromal HD and to evaluate the magnitude of differences across three fluency tasks. The results revealed that the HD+CLOSE and HD+DISTANT groups performed significantly more poorly in Design Fluency compared to non-carriers. The HD+CLOSE group also had significantly lower performance in phonemic and semantic fluency, while there were no differences between the HD+DISTANT group and non-carriers in the phonemic and semantic fluency tasks. The non-verbal fluency task resulted in a significant between-group difference also in errors as indexed by rule violations. Furthermore, the magnitude of differences for the carrier group was more pronounced in the non-verbal and phonemic fluency tasks compared to semantic fluency. PYTO was significantly correlated to performance on all fluency types.

Production of exemplars for non-verbal fluency and phonemic fluency tasks suggests that they are more sensitive indicators of cognitive function than semantic fluency in prodromal HD. Anatomically this is consistent with an expected effect of a disruption in the frontostriatal thalamocortical circuit present in $\operatorname{HD}[4,28]$. Based on the increasing evidence that striatal atrophy precedes the phenotypic expression of $\operatorname{HD}[17,20,23,50]$, it is plausible that the disruption in frontostriatal circuits starts before the appearance of motor symptoms. Higher scores in non-verbal and phonemic fluency are strongly related to the integrity of frontal circuits $[33,34]$, whereas semantic fluency also has a strong association with the temporal lobes $[51,52]$. Detectable differences in semantic fluency might therefore not occur until the symptomatic or near onset stages of the disorder. This could explain why our results contradict earlier findings that semantic and phonemic fluency are equally adversely affected in symptomatic HD [53].

Verbal fluency has been linked to left frontal lobe function and Design Fluency mainly to right frontal function [35, 54]. Our finding that non-verbal fluency, as measured by the free condition of Design Fluency [35], declines earlier than phonemic and semantic fluency, may be attributed to the higher eventual capacity required for the task. One possible explanation is that the initiating process of the free condition is more demanding and thus more sensitive than fluency tasks in fixed conditions, such as the fixed four-line task of Design Fluency [29, $35]$ or the Figure Fluency Test used by Hart et al. [29, 55]. Furthermore, phonemic fluency requires finding items stored in the individual's lexicon, while Design Fluency requires imagination of unknown designs not existing in any lexicon, i.e. directed search versus creative thinking. The less constrained nature of the task (drawing nonsense designs) may require more executive functions linked to the left and right frontal lobes [31]. An alternative explanation is that the task also taps visuospatial functions. Finally, another explanation is that emerging motor and cognitive dysfunction together lower performance $[12,15,56]$. 
Robins Wahlin et al.: Non-Verbal and Verbal Fluency in Prodromal Huntington's Disease

A potential explanation on a behavioural level for the observed pattern that non-verbal and phonemic fluency are more sensitive is connected to the executive demands of the tasks, which are related to initiation/retrieval capacities [57]. This hypothesis was put forward by Larsson et al. [32] in an earlier study involving semantic and phonemic fluency. Our findings are in line with this early study [32], and extend previous findings by using different fluency testing instruments. Non-verbal Design Fluency lacks explicit semantic and lexical demands and also lacks related memory components, i.e. the free condition of Design Fluency has a strong element of novelty, which is viewed as a hallmark of executive functions. Hence, results where carriers perform at a lower level in Design Fluency task support the hypothesis of the importance of executive demands, which seem to be compromised in both the HD+CLOSE and the HD+DISTANT group. The determining factor for enhanced performance could be the degree of structure inherent in the task at hand, i.e. the extent to which it requires self-initiated processing. The less structured a task, the greater the demands are to use an efficient search strategy and to exercise creativity in order to perform well. The degree of structure of the cognitive tasks in this study decreases along a continuum from semantic fluency, to phonemic fluency and further to non-verbal fluency. At the same time, cognitive resources required for successful execution increase, i.e. the demand for greater cognitive agility to initiate efficient search strategies and to draw on creative processing, increases along the same continuum. Executive dysfunction has also been suggested to underlie apparent prodromal HD deficits in general cognitive ability, as indexed by Wechsler Adult Intelligence Scale (table 2) [38, 58]. This view is also supported by the findings that performance IQ declines more rapidly than verbal IQ in prodromal HD [38]. There is evidence of the important role of executive demand and its impact on performance in various cognitive tasks, including fluency tasks, in studies of ageing [59-62]. This could also hold for prodromal HD as cognitive deficits occurring in HD and ageing resemble each other [63].

An important consideration when studying features of progressive disorders such as HD is the stage of the disease. In prodromal HD an approximation of disease stage is the time to disease onset based on CAG repeats [64,65]. Our findings, when dividing the carrier group into HD+CLOSE or HD+DISTANT from onset, indicate that non-verbal, phonemic, and semantic fluency are affected in the HD+CLOSE group. Interestingly, all fluency abilities correlated significantly with PYTO. The significant relationships align with the results of Jason et al. [66] who found overall cognitive functioning (a composite of different tasks) to be correlated with the number of CAG repeats. However, the composite measure of executive functioning (composite of Thurstone Word Fluency, Design Fluency, Wisconsin Card Sorting Test, Stroop Color, and Word Test) of Jason et al. [66] was not significantly correlated with CAG repeats. This could be due to the differing degrees of cognitive demand in the elements of the composite of different executive functioning tasks or due to the fact that they did not include age in the analyses.

Another crucial issue to consider is the choice of fluency tasks selected for assessment. It is likely that the various available categories used to measure semantic fluency differ in cognitive demand, depending on the number of possible targets in a specific category [67]. This may make it inappropriate to compare absolute levels in different semantic fluency tasks across studies. The category 'food' would be easier compared to 'fruits' and 'vegetables' that are often limited by the normal common knowledge of supermarket's supplies. Furthermore, cultural differences and education put limits on the categories as well. The most commonly used first letter tasks are only comparable in Germanic languages and would not be comparable for instance to the Finnish language. Regarding the S:A test, the Swedish language is rich with words starting with $\mathrm{S}$ and ending with $\mathrm{A}$, but at the same time the test is limited to the Swedish language. On the other hand, the non-verbal fluency task, such as Design Fluency (free condition), is not bound by language and could be compared internationally, but is unfortunately seldom used. Another methodological problem is that when non-verbal tests 
are used, the test centres choose 'fix conditions' such as lines or dots to be connected [55]. Importantly, the fact that absolute levels in fluency tasks are not easily compared across languages or cultures does not mean that they cannot be compared at the level of individual differences. There is a need for future research to disentangle which fluency tasks are most sensitive to clinical progression and which tasks are suitable for marking deficiencies at a very early stage.

Our results indicate that non-verbal fluency is essentially compromised earlier in the presymptomatic phase, followed by phonemic and semantic fluency in that order. Deficits in a specific fluency ability do not necessarily imply that this ability provides the most accurate measure of clinical progression. Snowden et al. [68] exemplify this assertion when arguing that deficiency in psychomotor speed has a more gradual onset, detectable earlier in the prodromal stage, than does the decline in memory abilities which only becomes apparent around the time of clinical diagnosis. It is plausible that psychomotor or motor deficits may affect performance on cognitive tests that are associated with motor performance [12] such as the Design Fluency test. However, Hart et al. [55] were not able to detect prodromal cognitive change with their Figure Fluency test, although they provided evidence for motor disturbances influencing symbol digit modalities test. This may be due to the fact that they used the modified Five-Point Test (Ruff Figural Fluency Test) $[29,69]$ that is a more structured and ruled task than the free condition of Design Fluency by Jones-Gotman and Milner [35].

Furthermore, Paulsen and co-workers $[12,56]$ note that associations between PYTO and cognitive dysfunction cannot be explained only on the basis of emerging motor signs. The results of the present study indicate that fluency performance in general is deficient in HD, and that decline in non-verbal and phonemic fluency marks abnormalities in prodromal stages. However, non-verbal and phonemic fluency are more sensitive indicators of cognitive change when measuring progression, based also on the greater effect sizes.

Verbal fluency tasks are often used in international studies $[14,70]$, but comparability is difficult as letters used vary between languages and task timing is different. This introduces a comparability problem, since the cognitive demand alters depending on both letters used and length of response time. Semantic fluency may not be suitable as a stand-alone early detection measure, but could be useful in comparison to phonemic fluency [70]. Unmack Larsen et al. [70] used phonemic design with alternating letters (lexical alternating fluency; letters $\mathrm{S}$ and $\mathrm{F}$ alternating with $\mathrm{K}$ and $\mathrm{B}$ ) and semantic/phonemic (semantic/lexical) alternating fluency and found these tasks were most frequently impaired in prodromal HD [70]. Interestingly, although they used experimental and traditional FAS fluency tasks, our results point in the same direction and support the statements that fluency tests seem to be very sensitive in detecting executive deficits in prodromal HD. Variations in the sensitivity to demands of fluency tasks have also been shown in normally ageing older adults [59].

Limitations to the results warrant mention. The small sample size restricts the power to detect subtle differences, and future studies with larger samples are required to confirm these results. For example, it is possible that a difference between HD+DISTANT and noncarriers in semantic and phonemic fluency does occur earlier, but that it is more subtle in degree than the differences in non-verbal fluency, and hence this study may lack the statistical power to detect such differences. Furthermore, it is important to remember that although we found significant differences between carriers and non-carriers, the distinction might be subtle. Regarding which measure is most sensitive for the detection of clinical progression, the majority of the findings to date derive from cross-sectional study designs that have certain drawbacks as compared to longitudinal designs. This highlights the importance of designing longitudinal studies, with prodromal samples assessing critical areas of cognition over time. However, these easily administered tasks, generally available to clinicians, demonstrate sensitivity to impairment in prodromal HD. 
To the best of our knowledge, this is the first study to compare non-verbal and verbal fluency performances in prodromal HD. This study demonstrates that fluency performance is a sensitive measure in distinguishing among groups with prodromal HD and distinguishing carriers and non-carriers. By studying specific critical areas of cognitive abilities there is the potential to observe a less ambiguous picture of early deficits in prodromal HD. This is important for our understanding of the course of the disease and is also of importance to the evaluation of clinical trials. In order to detect early signs of HD, it is recommended that a neuropsychological task in prodromal HD contains a minimum of inherent structure, thus increasing the executive demands. The pattern of results found in the present study emerges from a possible disruption of frontostriatal functioning, followed by more general dysfunction when the prodromal HD progresses to manifest HD. The novel finding that the tasks with high executive demands, such as non-verbal and phonemic fluency, are sensitive to detection of deviations from normal functioning makes the tests functional as follow-up tasks of prodromal HD. The Design Fluency drawings may be particularly sensitive as they tap creative ability and demand high executive functioning. These quickly administered fluency tasks show promise, not only as powerful tools potentially leading to a more precise assessment of phenoconversion, but also as valuable tools in neurological follow-up examinations of prodromal HD.

\section{Acknowledgment}

The authors thank the Department of Clinical Genetics, Karolinska University Hospital for assistance and all participants who generously gave their time to this project. This study was supported by a grant from the Swedish Research Council and Stockholm County Council, PickUp (grant No. 20050940 and 20070033), Sweden, to Tarja-Brita Robins Wahlin. The authors wish to thank Maria U. Larsson and Andreas Frick for their contribution towards data collection assessments over the years.

\section{References}

1 Brandt J, Butters N: The neuropsychology of Huntington's disease. Trends Neurol Sci 1986;9:118-120.

$\checkmark 2$ Duff K, Beglinger L, Theriault D, Allison J, Paulsen J: Cognitive deficits in Huntington's disease on the repeatable battery for the assessment of neuropsychological status. J Clin Exp Neuropsychol 2010;32:231-238.

-3 Beglinger LJ, Nopoulos PC, Jorge RE, Langbehn DR, Mikos AE, Moser DJ, Duff K, Robinson RG, Paulsen JS: White matter volume and cognitive dysfunction in early Huntington's disease. Cogn Behav Neurol 2005;18:102-107.

4 Montoya A, Price BH, Menear M, Lepage M: Brain imaging and cognitive dysfunctions in Huntington's disease. J Psychiatry Neurosci 2006;31:21-29.

5 Bates G, Harper PS, Jones L: Huntington's Disease, ed 3. Oxford, Oxford University Press, 2002.

6 Walker FO: Huntington's disease. Lancet 2007;369:218-228.

7 Robins Wahlin T-B, Lundin A, Dear K: Early cognitive deficits in Swedish gene carriers of Huntington's disease. Neuropsychology 2007;21:31-44.

-8 Kirkwood SC, Siemers E, Hodes ME, Conneally PM, Christian JC, Foroud T: Subtle changes among presymptomatic carriers of the Huntington's disease gene. J Neurol Neurosurg Psychiatry 2000;69:773-779.

-9 Lawrence AD, Weeks RA, Brooks DJ, Andrews TC, Watkins LH, Harding AE, Robbins TW, Sahakian BJ: The relationship between striatal dopamine receptor binding and cognitive performance in Huntington's disease. Brain 1998;121:1343-1355.

10 Lemiere J, Decruyenaere M, Evers-Kiebooms G, Vandenbussche E, Dom R: Cognitive changes in patients with Huntington's disease (HD) and asymptomatic carriers of the HD mutation - a longitudinal follow-up study. J Neurol 2004;251:935-942.

11 Soliveri P, Monza D, Piacentini S, Paridi D, Nespolo C, Gellera C, Mariotti C, Albanese A, Girotti F: Cognitive and psychiatric characterization of patients with Huntington's disease and their at-risk relatives. Neurol Sci 2002; 23:S105-S106.

12 Paulsen JS, Langbehn DR, Stout JC, Aylward E, Ross CA, Nance M, Guttman M, Johnson S, MacDonald M, Beglinger LJ, Duff K, Kayson E, Biglan K, Shoulson I, Oakes D, Hayden M: Detection of Huntington's disease decades before diagnosis: the Predict-HD study. J Neurol Neurosurg Psychiatry 2008;79:874-880. 
13 Robins Wahlin T-B, Byrne GJ: Cognition in Huntington's disease; in Tunali NE (ed): Huntington's Disease Core Concepts and Current Advances. InTech, 2012, pp 175-200.

14 Stout JC, Paulsen JS, Queller S, Solomon AC, Whitlock KB, Campbell JC, Carlozzi N, Duff K, Beglinger LJ, Langbehn DR, Johnson SA, Biglan KM, Aylward EH: Neurocognitive signs in prodromal Huntington disease. Neuropsychology 2011;25:1-14.

15 Musso M, Westervelt HJ, Long JD, Morgan E, Woods SP, Smith MM, Lu W, Paulsen JS: Intra-individual variability in prodromal Huntington disease and its relationship to genetic burden. J Int Neuropsychol Soc 2015;21:8-21.

16 You SC, Geschwind MD, Sha SJ, Apple A, Satris G, Wood KA, Johnson ET, Gooblar J, Feuerstein JS, Finkbeiner S, Kang GA, Miller BL, Hess CP, Kramer JH, Possin KL: Executive functions in premanifest Huntington's disease. Mov Disord 2014;29:405-409.

17 Harris G, Codori A, Lewis R, Schmidt E, Bedi A, Brandt J: Reduced basal ganglia blood flow and volume in presymptomatic, gene-tested persons at-risk for Huntington's disease. Brain 1999;122:1667.

18 Paulsen JS, Magnotta VA, Mikos AE, Paulson HL, Penziner E, Andreasen NC, Nopoulos PC: Brain structure in preclinical Huntington's disease. Biol Psychiatry 2006;59:57-63.

19 Dogan I, Eickhoff SB, Schulz JB, Shah NJ, Laird AR, Fox PT, Reetz K: Consistent neurodegeneration and its association with clinical progression in Huntington's disease: a coordinate-based meta-analysis. Neurodegener Dis 2013;12:23-35.

20 Wolf RC, Thomann PA, Thomann AK, Vasic N, Wolf ND, Landwehrmeyer GB, Orth M: Brain structure in preclinical Huntington's disease: a multi-method approach. Neurodegener Dis 2013;12:13-22.

-21 Aylward EH, Codori AM, Rosenblatt A, Sherr M, Brandt J, Stine OC, Barta PE, Pearlson GD, Ross CA: Rate of caudate atrophy in presymptomatic and symptomatic stages of Huntington's disease. Mov Disord 2000;15: 552-560.

22 Aylward EH: Change in MRI striatal volumes as a biomarker in preclinical Huntington's disease. Brain Res Bull 2007;72:152-158.

-23 Kipps CM, Duggins AJ, Mahant N, Gomes L, Ashburner J, McCusker EA: Progression of structural neuropathology in preclinical Huntington's disease: a tensor based morphometry study. J Neurol Neurosurg Psychiatry 2005;76:650-655.

24 Aylward EH, Sparks BF, Field KM, Yallapragada V, Shpritz BD, Rosenblatt A, Brandt J, Gourley LM, Liang K, Zhou H, Margolis RL, Ross CA: Onset and rate of striatal atrophy in preclinical Huntington disease. Neurology 2004; 63:66-72.

-25 Solomon AC, Stout JC, Johnson SA, Langbehn DR, Aylward EH, Brandt J, Ross CA, Beglinger L, Hayden MR, Kieburtz K, Kayson E, Julian-Baros E, Duff K, Guttman M, Nance M, Oakes D, Shoulson I, Penziner E, Paulsen JS: Verbal episodic memory declines prior to diagnosis in Huntington's disease. Neuropsychologia 2007;45: 1767-1776.

-26 Andrews TC, Weeks RA, Turjanski N, Gunn RN, Watkins LH, Sahakian B, Hodges JR, Rosser AE, Wood NW, Brooks DJ: Huntington's disease progression. PET and clinical observations. Brain 1999;122:2353-2363.

-27 Bäckman L, Robins Wahlin T-B, Lundin A, Ginovart N, Farde L: Cognitive deficits in Huntington's disease are predicted by dopaminergic PET markers and brain volumes. Brain 1997;120:2207-2217.

28 Tekin S, Cummings JL: Frontal-subcortical neuronal circuits and clinical neuropsychiatry: an update. J Psychosom Res 2002; 53:647-654.

29 Lezak MD, Howieson DB, Loring DW: Neuropsychological Assessment, ed 4. New York, Oxford University Press, 2004.

-30 Paulsen JS, Zimbelman JL, Hinton SC, Langbehn DR, Leveroni CL, Benjamin ML, Reynolds NC, Rao SM: fMRI biomarker of early neuronal dysfunction in presymptomatic Huntington's disease. AJNR Am J Neuroradiol 2004;25:1715-1721.

31 Baldo J, Shimamura A, Delis D, Kramer J, Kaplan E: Verbal and design fluency in patients with frontal lobe lesions. J Int Neuropsychol Soc 2001;7:586-596.

-32 Larsson MU, Almkvist 0, Luszcz MA, Robins Wahlin T-B: Phonemic fluency deficits in asymptomatic gene carriers for Huntington's disease. Neuropsychology 2008;22:596-605.

-33 Elfgren C, Risberg J: Lateralized frontal blood flow increases during fluency tasks: influence of cognitive strategy. Neuropsychologia 1998;36:505-512.

34 Frith C, Friston K, Liddle P, Frackowiak R: A PET study of word finding. Neuropsychologia 1991;29:1137-1148.

35 Jones-Gotman M, Milner B: Design fluency: the invention of nonsense drawings after focal cortical lesions. Neuropsychologia 1977;15:653-674.

-36 Harrington DL, Smith MM, Zhang Y, Carlozzi NE, Paulsen JS: Cognitive domains that predict time to diagnosis in prodromal Huntington disease. J Neurol Neurosurg Psychiatry 2012;83:612-619.

-37 van Walsem MR, Sundet K, Retterstøl L, Sundseth Ø: A double blind evaluation of cognitive decline in a Norwegian cohort of asymptomatic carriers of Huntington's disease. J Clin Exp Neuropsychol 2010;32:590598.

-38 Robins Wahlin T-B, Larsson M, Luszcz M: WAIS-R features of preclinical Huntington's disease: implications for early detection. Dement Geriatr Cogn Disord 2010;29:342-350.

-39 Robins Wahlin T-B, Bäckman L, Lundin A, Haegermark A, Winblad B, Anvret M: High suicidal ideation in persons testing for Huntington's disease. Acta Neurol Scand 2000;102:150-161.

40 Long JD, Paulsen JS: Multivariate prediction of motor diagnosis in Huntington's disease: 12 years of PREDICTHD. Mov Disord 2015;30:1664-1672. 
41 Folstein SE, Jensen B, Leigh RJ, Folstein MF: The measurement of abnormal movement: methods developed for Huntington's disease. Neurobehav Toxicol Teratol 1983;5:605-609.

42 Huntington Study Group: The unified Huntington's disease rating scale: reliability and consistency. Mov Disord 1996;11:136-142.

-43 Langbehn DR, Brinkman RR, Falush D, Paulsen JS, Hayden MR: A new model for prediction of the age of onset and penetrance for Huntington's disease based on CAG length. Clin Genet 2004;65:267-277.

44 Robins Wahlin T-B, Bäckman L, Lundin A, Haegermark A, Winblad B, Anvret M: High suicidal ideation in persons testing for Huntington's disease. Acta Neurol Scand 2000;102:150-161.

$\checkmark 45$ Langbehn DR, Hayden MR, Paulsen JS: CAG-repeat length and the age of onset in Huntington disease (HD): a review and validation study of statistical approaches. Am J Med Genet B Neuropsychiatr Genet 2010;153b:397408.

-46 Robins Wahlin T-B, Larsson MU, Luszcz MA, Byrne GJ: WAIS-R features of preclinical Huntington's disease: implications for early detection. Dement Geriatr Cogn Disord 2010;29:342-350.

47 Larsson MU, Luszcz MA, Bui TH, Robins Wahlin T-B: Depression and suicidal ideation after predictive testing for Huntington's disease: a two-year follow-up study. J Genet Couns 2006;15:361-374.

48 Nyman H: Neuropsychological Performance Related to Brain Morphology and Metabolism in Schizophrenia and Alzheimer's Disease. Stockholm, Karolinska Institutet, 1992.

49 Fernaeus SE, Almkvist 0: Word production: dissociation of two retrieval modes of semantic memory across time. J Clin Exp Neuropsychol 1998;20:137-143.

50 Wolf RC, Gron G, Sambataro F, Vasic N, Wolf ND, Thomann PA, Saft C, Landwehrmeyer GB, Orth M: Magnetic resonance perfusion imaging of resting-state cerebral blood flow in preclinical Huntington's disease. J Cereb Blood Flow Metab 2011;31:1908-1918.

51 Gourovitch M, Kirkby B, Goldberg T, Weinberger D, Gold J, Esposito G, Van Horn J, Berman K: A comparison of RCBF patterns during letter and semantic fluency. Neuropsychology 2000;14:353-360.

-52 Ho A, Sahakian B, Robbins T, Barker R, Rosser A, Hodges J: Verbal fluency in Huntington's disease: a longitudinal analysis of phonemic and semantic clustering and switching. Neuropsychologia 2002;40:1277-1284.

53 Henry JD, Crawford JR, Phillips LH: A meta-analytic review of verbal fluency deficits in Huntington's disease. Neuropsychology 2005;19:243-252.

54 Ruff RM, Allen CC, Farrow CE, Niemann H, Wylie T: Figural fluency: differential impairment in patients with left versus right frontal lobe lesions. Arch Clin Neuropsychol 1994;9:41-55.

-55 Hart EP, Dumas EM, Schoonderbeek A, Wolthuis SC, van Zwet EW, Roos RA: Motor dysfunction influence on executive functioning in manifest and premanifest Huntington's disease. Mov Disord 2014;29:320-326.

56 Paulsen JS: Early detection of Huntington's disease. Future Neurol 2010;5:85-104.

57 Monsch A, Bondi M, Butters N, Paulsen J, Salmon D, Brugger P, Swenson M: A comparison of category and letter fluency in Alzheimer's disease and Huntington's disease. Neuropsychology 1994;8:25-30.

58 Wechsler D: WAIS-R Manual Wechsler Adult Intelligence Scale-Revised (WAIS-R). New York, The Psychological Corporation, Harcourt Brace Jovanovich, 1981.

59 Bryan J, Luszcz M: Measures of fluency as predictors of incidental memory among older adults. Psychol Aging 2000;15:483-489.

60 Craik F, Byrd M, Swanson J: Patterns of memory loss in three elderly samples. Psychol Aging 1987;2:79-86.

61 Luszcz MA, Lane A: Executive function in cognitive ageing; in Hofer SM, Alwin DF (eds): The Handbook on Cognitive Ageing: Interdisciplinary Perspectives. Thousand Oaks, SAGE Publications, 2008, pp 193-206.

62 Luszcz MA: Executive function and cognitive aging; in Schaie KW, Willis SL (eds): Handbook of the Psychology of Aging, ed 7. Gurgaon, Elsevier India, 2010, pp 57-72.

63 Bäckman L, Farde L: Dopamine and cognitive functioning: brain imaging findings in Huntington's disease and normal aging. Scand J Psychol 2001;42:287-296.

64 Langbehn DR, Hayden MR, Paulsen JS: CAG-repeat length and the age of onset in Huntington disease (HD): a review and validation study of statistical approaches. Am J Med Genet B Neuropsychiatr Genet 2010;153B:397408.

65 Rubinsztein DC, Leggo J, Chiano M, Dodge A, Norbury G, Rosser E, Craufurd D: Genotypes at the Glu R6 kainate receptor locus are associated with variation in the age of onset of Huntington disease. Proc Natl Acad Sci USA 1997;94:3872-3876.

66 Jason GW, Suchowersky 0, Pajurkova EM, Graham L, Klimek ML, Garber AT, Poirier-Heine D: Cognitive manifestations of Huntington disease in relation to genetic structure and clinical onset. Arch Neurol 1997;54: 1081-1088.

67 Azuma T, Bayles K, Cruz R, Tomoeda C, Wood J, McGeagh A, Montgomery E: Comparing the difficulty of letter, semantic, and name fluency tasks for normal elderly and patients with Parkinson's disease. Neuropsychology 1997;11:488-497.

68 Snowden JS, Craufurd D, Thompson J, Neary D: Psychomotor, executive, and memory function in preclinical Huntington's disease. J Clin Exp Neuropsychol 2002;24:133-145.

-69 Ruff RM, Evans R, Marshall LF: Impaired verbal and figural fluency after head injury. Arch Clin Neuropsychol 1986;1:87-101.

70 Unmack Larsen I, Vinther-Jensen T, Gade A, Nielsen JE, Vogel A: Assessing impairment of executive function and psychomotor speed in premanifest and manifest Huntington's disease gene-expansion carriers. J Int Neuropsychol Soc 2015;21:193-202. 